\title{
Erratum to: Strontium ranelate changes the composition and crystal structure of the biological bone-like apatite produced in osteoblast cell cultures
}

\section{William Querido • Andrea P. C. Campos •}

Erlon H. Martins Ferreira • Rosane A. S. San Gil •

Alexandre M. Rossi • Marcos Farina

Published online: 17 July 2014

(C) Springer-Verlag Berlin Heidelberg 2014

\section{Erratum to: Cell Tissue Res}

\section{DOI 10.1007/s00441-014-1901-1}

The authors would like to call the reader's attention to the following:

The online version of the original article can be found at http://dx.doi.org/ 10.1007/s00441-014-1901-1.

W. Querido $\cdot$ M. Farina $(\triangle)$

Instituto de Ciências Biomédicas, Universidade Federal do Rio de Janeiro, 21941-902 Rio de Janeiro, RJ, Brazil

e-mail: mfarina@icb.ufrj.br

W. Querido

Instituto de Biofisica Carlos Chagas Filho, Universidade Federal do Rio de Janeiro, 21941-902 Rio de Janeiro, RJ, Brazil

\section{A. P. C. Campos • E. H. Martins Ferreira}

Divisão de Metrologia de Materiais, Instituto Nacional de

Metrologia, Qualidade e Tecnologia, 25250-020 Duque de Caxias,

RJ, Brazil

R. A. S. San Gil

Laboratório Multiusuário de RMN de Sólidos Professora Adelina Costa Neto, Universidade Federal do Rio de Janeiro, Rio de Janeiro, RJ, Brazil

\section{A. M. Rossi}

Grupo de Biomateriais: Preparação, Caracterização, Modelagem Teórica e Aplicações Biomédicas, Centro Brasileiro de Pesquisas Físicas, 22290-180 Rio de Janeiro, RJ, Brazil
Fig. 1 was unfortunately reproduced incorrectly. Below please find the corrected version:
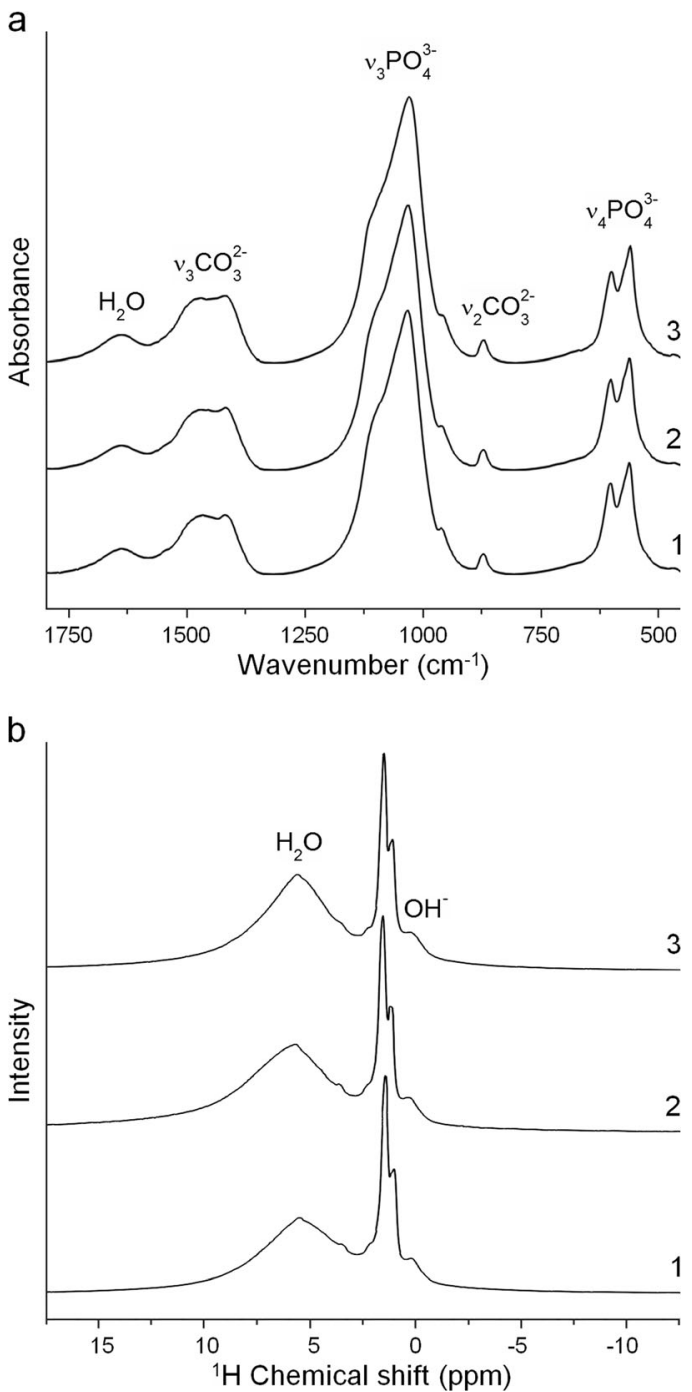